\title{
MATEO CEREZO, DIBUJANTE *
}

\author{
POR
}

\author{
ÁLVARO PIEDRA ADARVES **
}

\begin{abstract}
Among the less well-known aspects of Mateo Cerezo production he is that of their work like designer without a doubt. The present article analyses in depth this facet, showing its graphic techniques with the pencil (I last and fatty) and the similarities of its style with that of Carreño, until the point that some of its drawings have been attributed to its governor previously. Based on this it thinks about the disjunctive Carreño-Cerezo putting in cloth of trial works previously attributed to the teacher like the semi-nude Christ and the San Stigmatised Francisco, of the Museum of the Prado. Also they are attributed with some certainly to Cerezo preparatory models, patterns of heads, bodies and figures that show the continuous use of the pencil in the preparation of their canvases.
\end{abstract}

Entre los aspectos menos conocidos de la producción del malogrado artista burgalés Mateo Cerezo (1637-1666) se encuentra sin duda el de su labor como dibujante.

Encarecida ya por Palomino al analizar el dibujo de sus cuadros ${ }^{1}$, uno de los primeros sin embargo en hacer una estricta referencia a su actividad gráfica fue el historiador William Bürger (seudónimo de Theophile Thoré) en 1884, quien en su artículo monográfico sobre el artista ensalzó sus «excelentes dibujos, muy vivos y muy expresivos», comparando su estilo con los arquetipos estéticos imperantes en ese momento - no siempre ajustados a su arte- de Murillo y Van Dyck: «... recuerdan — dice Bürger - la manera de Murillo y la de Van Dyck...» ${ }^{2}$.

Aunque este autor sólo consignó un dibujo a lápiz de un Cristo muerto llorado por las Santas mujeres (Museo del Prado), antaño atribuido por Ceán Bermúdez y actualmente no considerado por la crítica ${ }^{3}$, su apreciación en realidad se hizo eco de los diseños que hasta ese

\footnotetext{
* A Antonio Jesús Piedra Adarves.

** Agradezco a Rocío Arnáez la facilidad para estudiar los dibujos del Museo del Prado.

1 Palomino y Velasco, A. A., Museo Pictórico y Escala Óptica con El Parnaso Español Pintoresco Laureado, Madrid, 1715-1724 (reimpreso en 3 vols. por la Edit. Aguilar en 1988, por la que se cita). Vol. 3, pp. 331-334.

2 Bürger, W., «Mateo Cerezo», sin paginar, en Charles Blanc, Histoire des peintres de toutes les écoles, París, 1884. Existe traducción al español por Elías Tormo en su trabajo monográfico sobre el pintor «Mateo Cerezo», Archivo Español de Arte y Arqueología, 1927, pp. 113-128 y 245-274 (262-266), con apreciaciones y correcciones del autor, por la que se cita. Para los dibujos, véase la p. 264. Este mismo autor ya trató lo habitual de la influencia vandyckiana en la pintura barroca madrileña (pp. 251-254), y lo inviable del influjo de Murillo en el caso de Cerezo (pp. 267-274).

${ }^{3}$ El diseño fue citado por Ceán Bermúdez en su Diccionario histórico de los más ilustres profesores de las Bellas Artes en España, Madrid, 1800, t. 1, p. 312, afirmando que «manifest(aba) el dibujo de sus lienzos». Tras varias ventas pasó al Museo del Prado, en cuyo catálogo se consideró ajeno a su estilo. Pérez Sánchez, A. E., Museo del Prado. Catálogo de dibujos. I. Dibujos españoles, siglos XV-XVII, Madrid, 1972, p. 141. Se cree obra del siglo XVIII.
} 
momento circulaban atribuidos a su mano en el comercio artístico de su país, algunos de los cuales se habían coleccionado anteriormente por otro historiador francés, Paul Lefort, quien llegó a reunir el «Cristo muerto» de Ceán y varios más a pluma: un Paisaje, Dos cabezas de ángeles y un Enterramiento de Cristo (en paraderos desconocidos) ${ }^{4}$, que — de ser suyossuponen hoy los únicos testimonios que se conocen de esta práctica gráfica.

En la actualidad el «Corpus» de los dibujos de Mateo Cerezo se ha llevado a cabo por los investigadores José R. Buendía e Ismael Gutiérrez en una monografía que dedicaron al pintor en $1986^{5}$. En ella se dejó planteado un catálogo razonado de once dibujos — van signados de D1 a D11-, de los cuales uno - el D11-, sin perder una antigua atribución de Mayer, se conceptuó ajeno a los modos de Cerezo ${ }^{6}$, y cinco —el D1, D2, D5, D6 y D10 - fueron desatribuidos posteriormente por el profesor Pérez Sánchez en la revisión y aportación que hizo del arte de Cerezo en $1987^{7}$. Pérez Sánchez, no obstante, consideró que el D1, un estudio de Dos ángeles niños (antigua col. Boix de Madrid) ${ }^{8}$ (Fig. 1) podría ser obra de Cerezo y corresponder a su período juvenil.

En efecto, el dibujo concuerda bastante con algunas parejas de angelitos que aparecen en sus cuadros más tempranos, como el de la Asunción de la Virgen (1659) del convento de Jesús y María de Valladolid y el recientemente dado a conocer del Abrazo de San Francisco y Santo Domingo del convento de las Descalzas Reales de la misma ciudad (h. 1659) ${ }^{9}$. Estos angelitos, sin ser ciertamente idénticos al dibujo, remiten su forma mecánica de concebir a un niño sin tenerle presente, desde la manera de representar la cabeza - cabellos, nariz, mentón-, hasta el vientre ligeramente abultado con el ombligo hundido. Su técnica también guarda estrechas semejanzas con el arte gráfico del pintor, ya sea la manera de acentuar los perfiles como la rotundidad volumétrica de las figuras con gran sentido escultórico, que Cerezo seguramente asimiló en el taller de su padre, especializado en la copia de esculturas ${ }^{10}$.

Así pues, del «Corpus» de 1986 quedan como dibujos de Cerezo: los ya referidos Dos angelitos de la col. Boix, un asombroso Cristo crucificado del Museo del Prado ${ }^{11}$; una Virgen

\footnotetext{
${ }^{4}$ Dichos dibujos se dispersaron en París a la venta de la colección en 1869. Lefort, P., Catalogue de la Collection de Dessins Anciens des Maîtres Espagnols, Flamandas, Français, Hollandais et Italiens, composant le Cabinet de M. Paul Lefort, París, 1869. El «Paisaje» que se consignó a pluma, ha de ser el mismo que el atribuido a Cerezo en la venta parisina de Dessins de la coll. Salla, realizada en 1873 con el núm. 25. Recientemente ha salido a la venta en Nueva York un dibujo a pluma atribuido a Cerezo que representa a «Cristo flanqueado por la Virgen, San Juan Evangelista, y dos Santos» (Old Master Drawings, New York, 1995, Cat. Subastas Christie's, p. 78, n. 72). Su estilo, sin embargo, difiere de lo que conocemos del artista, siendo probablemente de escuela italiana. Lleva una inscripción del siglo XIX con el nombre de «Matteo Cereza».

5 Buendía, J. R. y Gutiérrez, I., Vida y obra del pintor Mateo Cerezo (1637-1666), Burgos, 1986. Apartado VI. 3. Catálogo de Dibujos (pp. 199-213). Tiene además otro muy útil (VI.4) con las referencias de aquellos «citados de antiguo y atribuidos», pp. 215-217.

6 Buendía y Gutiérrez, p. 212.

7 Pérez Sánchez, A. E., «Revisión de Mateo Cerezo. A propósito de un libro reciente», Archivo Español de Arte (A.E.A.), 1987, pp. 281-297. En cuanto a los dibujos que entonces se consideraron suyos conviene observar la semejanza formal del D3, unos Desposorios místicos de Santa Gertrudis, de la Galería florentina de los Uffizi (Buendía y Gutiérrez, pp. 200202), con el estilo de Francisco Solís, a quien se puede atribuir este dibujo, particularmente por el modelo de la Virgen, afín - entre otras - a la de su «Visión de Santa Magdalena de Pazzis del Colegio vallisoletano de los Ingleses, y por el Niño Jesús, similar al de su «Huida de Egipto» del Palacio Real de Madrid.

$8250 \times 150 \mathrm{~mm}$. A lápiz negro con clarión. Lleva una inscripción con letra del siglo xvir creída autógrafa: «Matheo»; y otra del siglo XviII «Matheo Zereso». Buendía y Gutiérrez, p. 199.

9 Martín González, J. J., «Sobre Mateo Cerezo», Boletín del Seminario de Estudios de Arte y Arqueología (B.S.A.A.), 1987, pp. 403-404.

${ }^{10}$ Gran parte de su producción la consagró en copiar la famosa escultura del «Cristo de Burgos», más conocido por el «Cristo de los tres huevos». Sobre Mateo Cerezo padre, véase el estudio de Buendías y Gutiérrez, pp. 16-20.

11 Presenta recortes. $290 \times 186 \mathrm{~mm}$. A lápiz negro con toques de clarión. Inscripción con letra del siglo xVir creía autógrafa: «Matheo Cerezo en un recorte añadido. El dibujo, con influencia canesca, parece un esquema libre de sus Cristos de la Catedral de Burgos y del Staatliche Museen de Berlín. Buendía y Gutiérrez, pp. 207-208. (Cat. D7).
} 

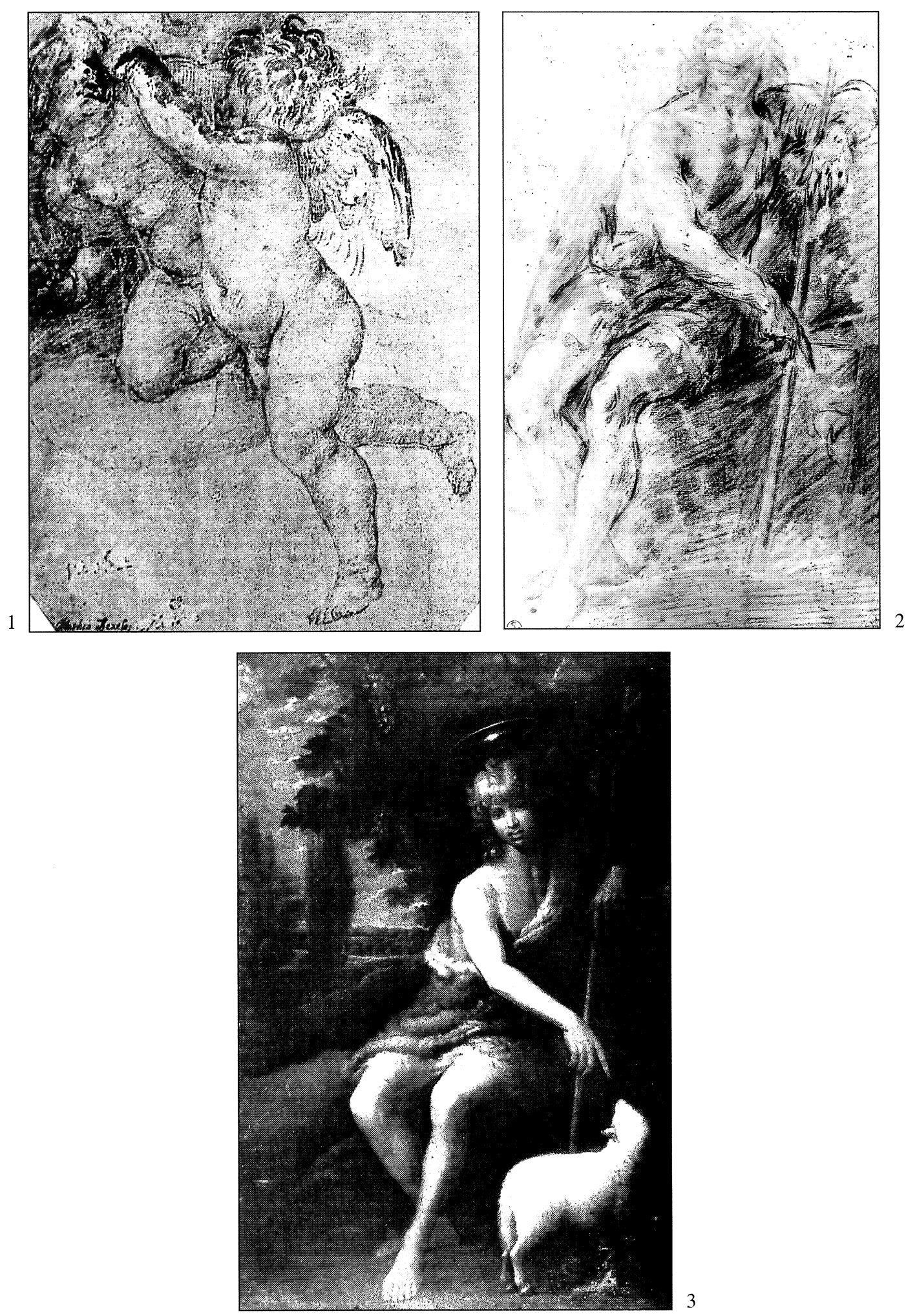

Fig. 1. Cerezo: Dos angelitos. Antigua col. Boix. Madrid.

Fig. 2. Cerezo: San Juan Bautista.Museo de los Uffizi. Florencia.

Fig. 3. Cerezo: San Juan Bautista. Col. part. guipuzcoana. 
con el Niño adorado por santos de la madrileña Academia de San Fernando ${ }^{12}$, y varios dibujos de la Biblioteca Nacional de Madrid, atribuidos por Barcia en 1906, a saber: un Cristo en la flagelación con su reverso de una Gloria angélica ${ }^{13}$, y dos agilísimos apuntes en una misma cara de hoja con una Gloria y un San Mateo que por su ejecución un tanto «cristalina» parecen diferir de los anteriores ${ }^{14}$.

Ateniéndonos por tanto a sus dibujos más seguros, vemos cómo Cerezo gusta de emplear el lápiz negro graso con toques de clarión combinando el trazo fino y continuo, con lápiz duro, para perfiles y diseños definitivos — como los «Dos angelitos»- y la raya corta y quebrada, con lápiz blando, para tanteos y «rasguños» de los que su mejor exponente acaso sea el «Cristo crucificado».

Este tipo de técnica heredera en su origen de los pintores italianos que trabajaron en El Escorial durante el primer cuarto de siglo, concretamente de Vicente Carducho, se vincula directamente con el estilo gráfico de su maestro Carreño, hasta el punto de que algunos de los dibujos que presentamos a continuación como originales de Cerezo han pasado en ciertos momentos por obras seguras del pintor asturiano,

Esta semejanza técnica, difícil de establecer incluso para sus mismos coetáneos, fue advertida ya por Palomino, quien comentó de Cerezo que «totalmente le bebió el espíritu a su maestro, pues ninguno de los muchos discípulos que tuvo, llegó a imitarle tanto; de suerte, que es menester mucho, para distinguir sus obras de las de Carreño» ${ }^{15}$.

Así, el primer dibujo que adscribimos a la producción gráfica de Mateo Cerezo es un interesante San Juan Bautista conservado en el Museo de los Uffizi florentinos ${ }^{16}$ (Fig. 2).

La obra se puso ya en relación con el taller de Carreño por Pérez Sánchez, quien tras advertir su semejanza formal con un cuadro de Mateo Cerezo del mismo tema, de colección particular madrileña (h. 1664-1665), se inclinó finalmente por el pintor asturiano al considerar que el diseño apenas tiene correspondencia con la composición del lienzo un tanto forzada en la posición del modelo.

La comparación del dibujo con otro San Juan Bautista de Mateo Cerezo firmado en 1662, de colección particular guipuzcoana ${ }^{17}$ (Fig. 3), permite corroborar, no obstante, la atribución de Pérez Sánchez al pintor burgalés, pues el cuadro resume de forma fidedigna casi todos los planteamientos técnicos que se observan en el diseño, desde la postura helicoidal del Santo a través de la misma disposición de brazos, manos, piernas y pies, hasta el vellón terciado que cubre su cuerpo o el cayado en que se enlaza. Sólo se observan diferencias en la representación del entorno que no aparece en el estudio salvo con una brevísima alusión a la roca donde permanece sentado «El Precursor» y en la posición de la cabeza, que mira hacia arriba y que está más en consonancia con el cuadro madrileño. Por su parte, este último se ajusta más al diseño en la masculinización del personaje.

12 Id., p. 202 (Cat. D4). $201 \times 165$ mm. A lápiz negro. A mi modo de ver, el dibujo advierte semejanzas formales con el estilo de Claudio Coello, especialmente en la profusión de elementos y en el aglomeramiento de los personajes.

13 Id., pp. 207-210 (Cat. D8r y D8v). 284 × 162 mm. A lápiz negro. Inscripción en la parte recta con letra del siglo xVII: «Çereço»; otra con «Solís» (acaso como propiedad). Al dorso inscripción con letra moderna «Dibujo pa. cuadro que posee el Conde Adanero (?)».

14 Id., pp. 210-211 (Cat. D9). $278 \times 197$ mm. A lápiz negro. A este mismo estilo pertenece también un dibujo de una Aparición de la Virgen con el Niño a San Francisco de la Biblioteca Nacional de Madrid (A.M. Barcia, Catálogo de la colección de dibujos de la Biblioteca Nacional, Madrid, 1906, p. 74, núm. 353), que tras creerse obra de Murillo fue puesto en relación con el arte de Cerezo por J. Brown (Murillo \& His Drawings, Princeton, 1976, p. 185, núm. x-7).

15 Palomino y Velasco, vol. 3, p. 332

${ }^{16}$ Núm. Cat. 10122 S. Presenta recortes. $375 \times 230$ mm. EXPO, Mostra di disegni spagnoli (Catálogo por Alfonso Pérez Sánchez), Firenze, Gabinetto disegni e estampe degli Uffizi, Florencia, 1972, p. 98, núm. 108, lám. 83; Id., «Dibujos españoles en los Uffizi florentinos», Goya, 1972, pp. 155-156.

17 Buendía y Gutiérrez, lám. p. 94, núm. cat. 37, p. 135. 
El dibujo, no obstante, podría considerarse un modelo de Carreño empleado por Cerezo, si bien la insistencia del pintor burgalés en reutilizar este esquema para sus composiciones más notorias, tal como hizo con su «Cristo crucificado», y la ausencia de ejemplos pictóricos concretos en la producción del maestro asturiano, hacen estimar al dibujo como una creación original de Mateo Cerezo. En todo caso, el dibujo puede considerarse un patrón o «esquema» (más que un modelo preparatorio) modificado por el artista en algunas de sus partes, bien a su libre albedrío, o bien ya al del comitente ${ }^{18}$.

Es interesante señalar para mayor complicación que la cabeza de este «San Juan Bautista» presenta estrechas semejanzas fisonómicas con una que plasmó Carreño en su San Sebastián del Museo del Prado (1656). Cuadro de gran éxito en aquel momento, cuya ejecución en 1656 coincide plenamente con el discipulaje de Cerezo en el taller del pintor asturiano.

En cualquier caso, la técnica del dibujo deriva de Carreño, sobre todo en la manera de acometer los trazos y en el uso combinado de varios lápices, a pesar de que el estilo de Cerezo se muestra aquí bastante original al ser más robusto y enérgico que el del pintor asturiano. Sus sombras y sus efectos de luz se hacen de forma rápida, y sobre todo lo que más le interesa al artista es la funcionalidad del esquema. Como en su «Cristo crucificado» Cerezo ha aprehendido las sugerencias de las formas a través de una síntesis compositiva en la que un juego de líneas fundamentalmente discontinuas y abreviadas delimitan en pocos trazos los perfiles de las figuras. Líneas que son remarcadas posteriormente en algunos de sus tramos con un subrayado intenso del lápiz graso haciendo dotar a las imágenes de una ligerísima vibración e inestabilidad que las sumerge en una atmósfera suave de luces y sombras muy acorde con la sensibilidad artística de la época hacia el venecianismo del «cinquecento».

Este movimiento vacilante de los personajes, característico del estilo más personal de Cerezo — recuérdese la sensación vibratoria de su «Cristo crucificado» del Prado— se refuerza aún más por medio de un sombreado paralelo alrededor de las siluetas que las hace despegar por completo de su entorno creando un gran sentido pictórico más efectivo en este «San Juan Bautista» por la combinación del lápiz negro con el ocre.

El dibujo también se puede comparar técnicamente con un diseño de Cristo semidesnudo del Museo del Prado ${ }^{19}$, considerado tradicionalmente de Carreño pero cuyo torso y cabeza reproduce el mismo modelo que Cerezo empleó en su San Juan Bautista bautizando a Cristo de la iglesia parroquial de Santo Domingo de Guzmán, en Castrojeriz (Burgos) (h. 16581659) ${ }^{20}$. ¿Nos encontramos, pues, ante un dibujo de Carreño utilizado por Cerezo en sus principios? o ¿ante un dibujo de Cerezo considerado tradicionalmente de Carreño? En cualquier caso la técnica es prácticamente la misma y las respuestas a estos interrogantes sólo se podrán dilucidar cuando se aborde íntegramente el catálogo de dibujos del gran pintor asturiano.

En esta misma disyuntiva estilística «Carreño-Cerezo» se encuentra también otro dibujo de una Academia masculina conservado como anónimo en el Museo del Prado (Fig. 4) ${ }^{21}$.

La obra representa a un hombre desnudo con el dorso de espaldas sentado sobre un tejido revuelto. Lleva anudado en la cabeza un pañuelo que da gran naturalidad a la composición y sus brazos - uno sujetando una vara y otro apoyado en el suelo- establecen una espectacular diagonal que recuerda la forma de algunas figuras de Ribera.

\footnotetext{
18 A este respecto Julio Cavestany ya apuntó lo desconcertante que resulta la cabeza del cuadro guipuzcoano en relación con la posición del cuerpo, sugiriendo que su visión frontal seguramente se debió a alguna imposición del cliente que encargó la obra («Un cuadro firmado por Mateo Cerezo», Arte Español, 1941, pp. 18-20).

${ }_{19}$ F.D. 128. Pérez Sánchez, Ob. cit. Museo del Prado, 1972, p. 72.

${ }^{20}$ Buendía y Gutiérrez, lám. p. 37, cat. 12, pp. 115-116.

$21285 \times 410$. Pérez Sánchez, A. E., Museo del Prado. Catálogo de Dibujos. III. Dibujos españoles, siglo Xvill (C-Z), Madrid, 1977. F.D. 2497, p. 163.
} 
El dibujo se puso ya en relación con el taller de Carreño por Pérez Sánchez y su técnica es bastante afín a la de Cerezo en la combinación del lápiz negro con el clarión — su fórmula más habitual- y en la recurrencia a las sombras oscuras en forma de manchones junto a los contornos de las figuras para despegarlas del entorno. Su forma de tratar la anatomía es también muy similar: obsérvese la ejecución de los bíceps, casi idénticos a los del «San Juan Bautista» florentino. Esto unido a cierta sequedad en el «asiento» general del modelo, hacen pensar más en un diseño de Mateo Cerezo que en uno de Carreño.

Otro dibujo que se puede también poner en relación con el cuadro anteriormente citado del «San Juan Bautista» madrileño es una Cabeza juvenil conservado asimismo en el Museo del Prado ${ }^{22}$ (Fig. 5).

El diseño que creemos obra de Cerezo demuestra hasta qué punto el artista pensó de forma pormenorizada la composición de sus figuras, especialmente la de sus «Bautistas», a pesar de que su esquema general con ligeros recuerdos canescos derive, como ya apuntó Pérez Sánchez, de los prototipos riberescos usados por su maestro en algunos de sus lienzos más famosos, como el de la Magdalena de la Academia ${ }^{23}$.

Esta cabeza completa en detalle los ligeros esbozos que hizo Cerezo en el dibujo de los Uffizi teniendo todas las particularidades del rostro: perfil, cabellos y labios semientreabiertos, una fiel correspondencia con el lienzo madrileño a excepción de la mirada algo más elevada.

Como en el caso de sus anteriores dibujos, este modelo de cabeza fue previamente aprovechado por Cerezo en su Santa Isabel de Hungría del convento vallisoletano de Jesús y María (1659) (Fig. 6) ${ }^{24}$, lo que permite considerar al diseño una obra de su período juvenil cercana a los «Dos angelitos» de la col, Boix.

En cuanto a su técnica se puede decir que es la habitual de Cerezo en estos primeros años. Establece perfiles muy marcados con un gran sentido escultórico y coordina hábilmente el lápiz negro con la sanguina a fin de conseguir una mayor corporeidad llena de sugestión flamenco veneciana y resumir con grandes efectos pictóricos la idea definitiva de lo que vas a plasmar en el lienzo.

Su dependencia con los arquetipos de Carreño es también estrecha - recuérdese por ejemplo la cara de la Magdalena de la Academia_, si bien el concepto estético que plasma Cerezo en este rostro juvenil, mucho más epicúreo que los realizados habitualmente por el pintor asturiano, es su típico ideal de belleza transferido a sus personajes.

Vemos, por tanto, cómo en estos dibujos Mateo concibe el estudio de la figura humana de forma fragmentada, tratando por un lado la cabeza y por el otro el esquema del cuerpo en sus estructuras y movimientos más fundamentales. Tal proceso de composición por partes permite adentrarnos un tanto en su método de trabajo que debió basarse seguramente en un amplio muestrario de dibujos (cabezas y cuerpos) combinados a modo de un «rompecabezas» según fuese el tema (o gusto) a representar (o a componer).

Siguiendo este supuesto muestrario técnico se pueden atribuir a continuación varios dibujos de cabezas y cuerpos que reflejan en cualquier caso los pasos del artista como dibujante, y que van desde «rasguños» o ligeros apuntes hasta «modelos» definitivos muy elaborados, pasando por composiciones con varios personajes seguramente preparatorias para encargos concretos.

Conviene señalar que su maestría en cada tipo de diseño no hubo de depender tanto de su madurez profesional como de la frecuencia con que el artista abordó un tema determinado. Es

\footnotetext{
22 F.D. $1163.210 \times 152$ mm. Pérez Sánchez, Ob. cit. Museo del Prado, 1972, p. 75, lám. 29a.

${ }^{23}$ Id., Juan Carreño de Miranda, Avilés, 1985, p. 50.

${ }^{24}$ Buendía y Gutiérrez, lám. p. 36, cat. 6, pp. 113-114.
} 


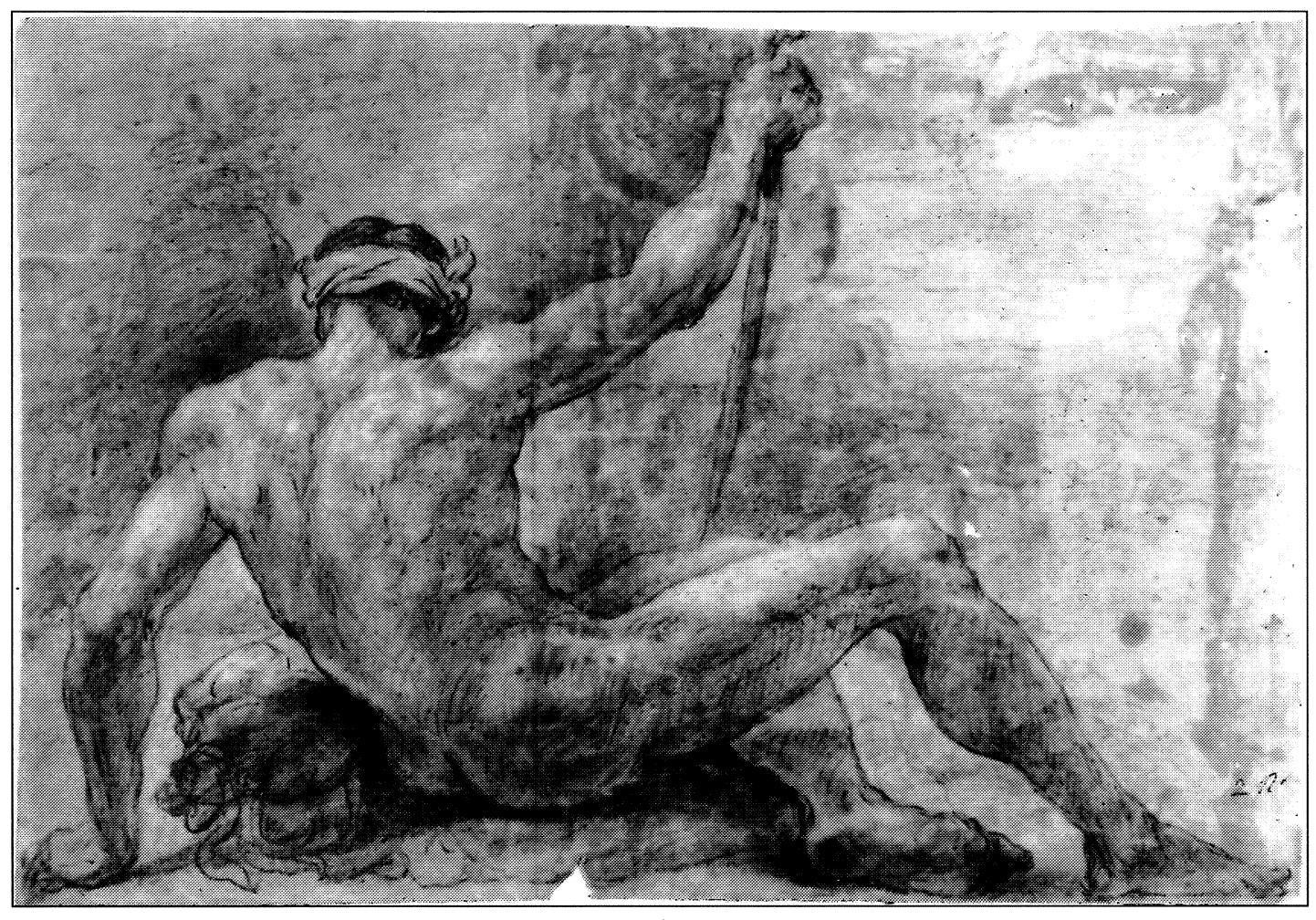

4

5
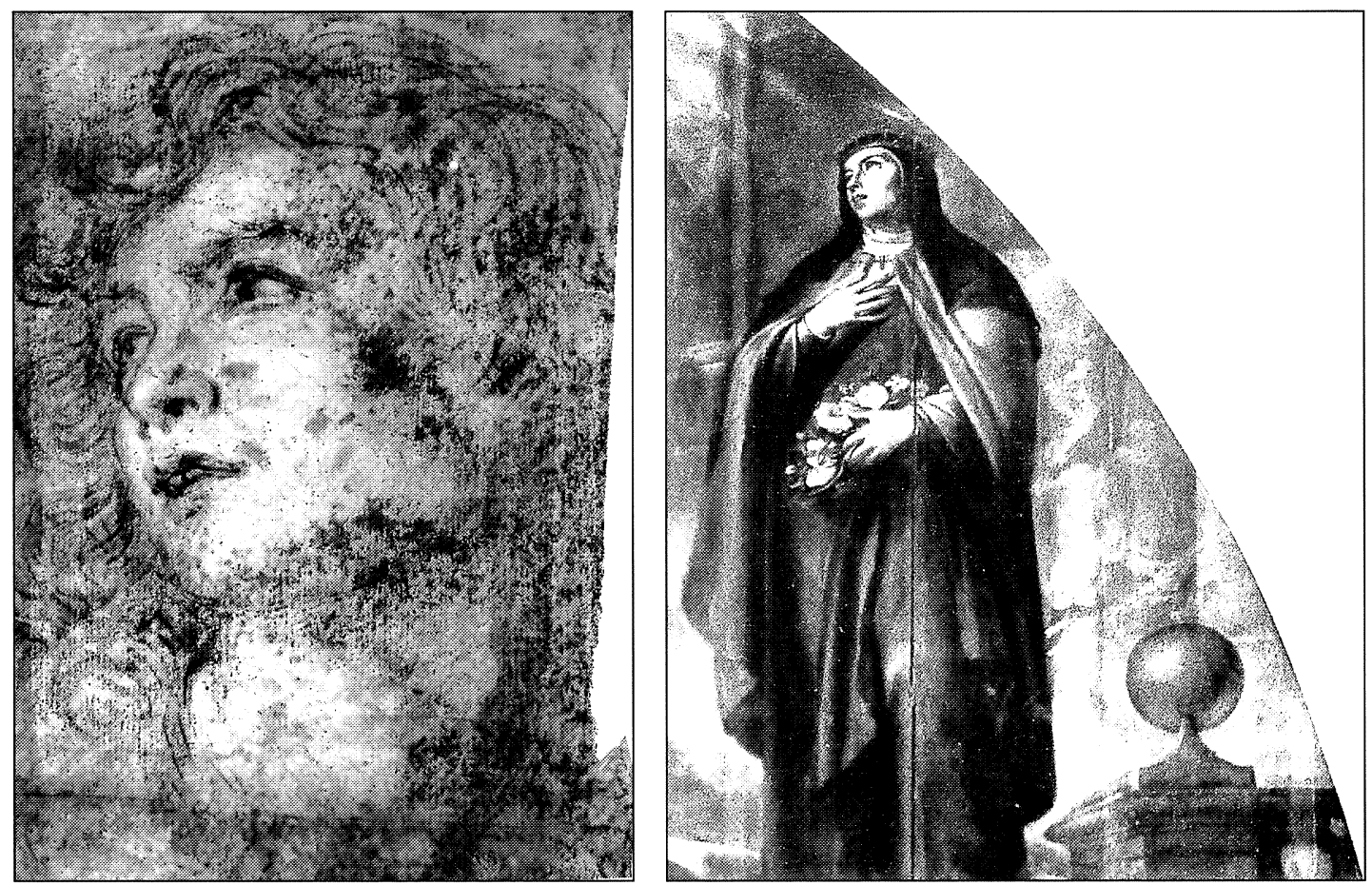

Fig. 4. ¿Cerezo? Academia. Museo del Prado.

Fig. 5. Cerezo: Cabeza juvenil. Museo del Prado.

Fig. 6. Cerezo: Santa Isabel de Hungría. Convento de Jesús y María. Valladolid. 
obvio que una composición como la de Cristo en la cruz, tan cara al pintor y con tan sobresalientes ejemplos en su catálogo (Catedral de Burgos, Museo de Arte Decorativo de Buenos Aires, Staatliche Museum de Berlín, etc.), debió de serle bastante fácil. Hecho que acaso explique un «rasguño» tan magistral como el del «Cristo crucificado».

Siguiendo, pues, con los dibujos de cabezas, generalmente muy acabados y con un carácter de «modelo» — según hemos visto en la «Cabeza juvenil»—, se pueden adscribir al artista varios que reflejan su destreza con el lápiz y su plena dedicación a esta parte del cuerpo humano como una de las más reclamadas por el comitente.

La primera es una formidable Cabeza femenina atribuida a Carreño en la Biblioteca Nacional de Madrid (Fig. 7) ${ }^{25}$.

De fuerte sabor canesco, pues recuerda bastante en su tratamiento de ojos y cejas muy oblicuos a una escultura de «San Antonio de Padua» de la iglesia de San Nicolás de Murcia ${ }^{26}$, está realizada a lápiz negro y se corresponde plenamente con la cara de un ángel que aparece en su San Francisco estigmatizado del Museo del Prado ${ }^{27}$ (Fig. 8). Dicho ángel está situado en la parte izquierda de la composición, derecha del santo.

Su rostro está concebido en un logrado escorzo que le hace mirar hacia abajo de forma oblicua y posee los mismos rasgos fisonómicos que los del ángel del lienzo: cejas arqueadas muy finas, ojos rasgados con abundantes y sensuales pestañas, y boca con ligera prolongación de la comisura derecha (izquierda del espectador) para facilitar la sensación de giro instantáneo.

Es interesante advertir su ligera semejanza formal con el rostro velazqueño de La Mulata de la National Gallery of Ireland (Dublín).

$\mathrm{Al}$ igual que su «Cabeza juvenil», Cerezo ha empleado aquí el lápiz duro haciendo perfiles muy remarcados y modelando la materia a base de rayitas paralelas muy finas.

Se trata, por tanto, de otro «patrón» que el pintor ajustó a esta composición modificándole ligeramente en la posición del cuerpo. Nótese cómo en el dibujo el hombro está cubierto por una pañoleta y echado hacia adelante mientras que en el cuadro, sin pañoleta, se eleva para abrazar al Santo.

También conviene indicar que en la parte superior de la cabeza, junto al cabello, está representada una rosa muy naturalista que hace ver cómo Cerezo aprovechó al máximo los soportes de sus dibujos con cualquier apunte superfluo, lo que acaso justifique un tanto los recortes que se aprecian en éste y en otros muchos de sus diseños seguramente discriminando esos ligeros apuntes que el artista hacía de menor tamaño que la figura principal. Esta hipótesis podría mostrarnos su forma de trabajar ¿caótica? y la funcionalidad de su muestrario, que podría aglutinar en una misma hoja de papel diversos patrones de cabezas, cuerpos, flores u otros objetos sin aparente relación.

La cabeza se podría fechar en torno a 1664 junto con el cuadro de San Francisco estigmatizado si consideramos su similitud estilística con la de un ángel sosteniendo la palma en el lienzo de la Inmaculada Concepción del Museo del Ermitage ${ }^{28}$, firmado y fechado ese mismo año.

Con respecto a la figura de San Francisco estigmatizado es interesante observar su semejanza formal con un dibujo del mismo asunto atribuido a Carreño en el Museo del Prado ${ }^{29}$

$25145 \times 120 \mathrm{~mm}$. Barcia, p. 60, núm. 278.

26 Wethey, H. E., Alonso Cano. Pintor, escultor y arquitecto, Madrid, 1983, lám. núm. 143.

27 Buendía y Gutiérrez, lám. p. 55, cat. 75, p. 164

${ }^{28}$ Kagané, L., «Tres pinturas españolas en Rusia: los retratos de Juan de Austria de Alonso Sánchez Coello, de Camilo Astalli Pamphili del taller de Velázquez y la "Inmaculada Concepción” de Mateo Cerezo», A.E.A., 1994, pp. 274-275, fig. 3 .

${ }^{29}$ F.A. 72. Pérez Sánchez, Ob. cit., Museo del Prado, 1972, p. 73, lám. 26. 


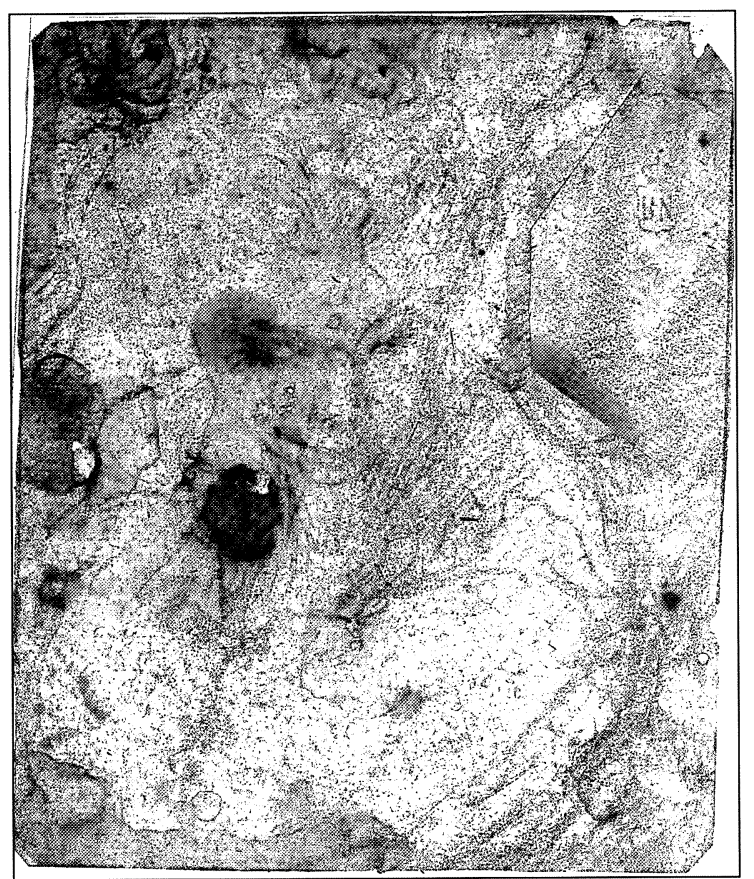

7

\section{9}

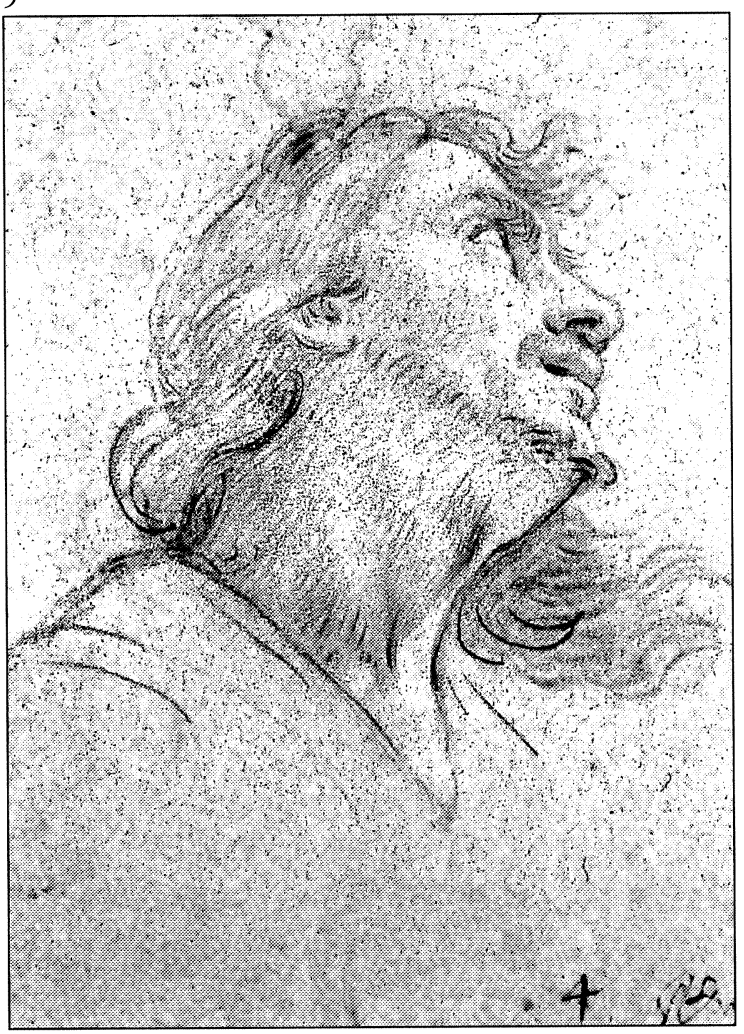

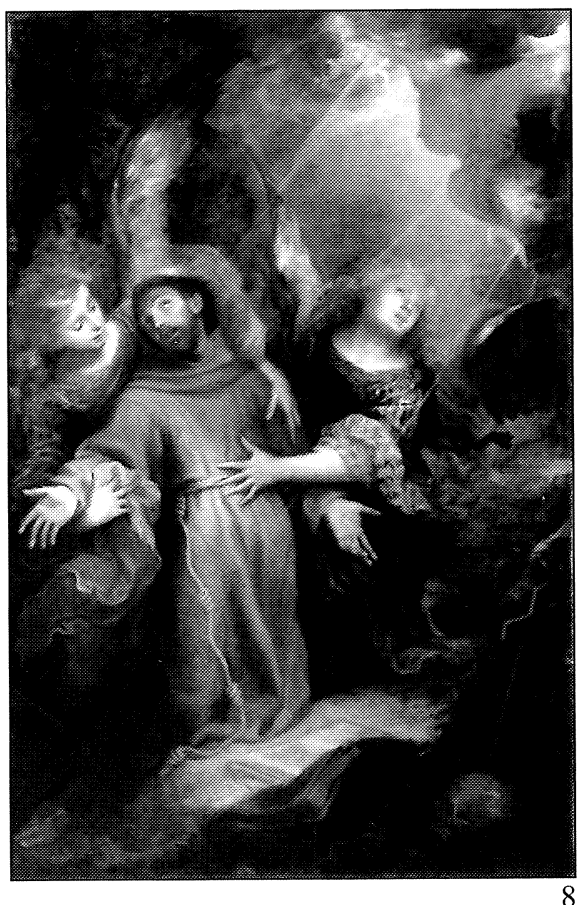

10

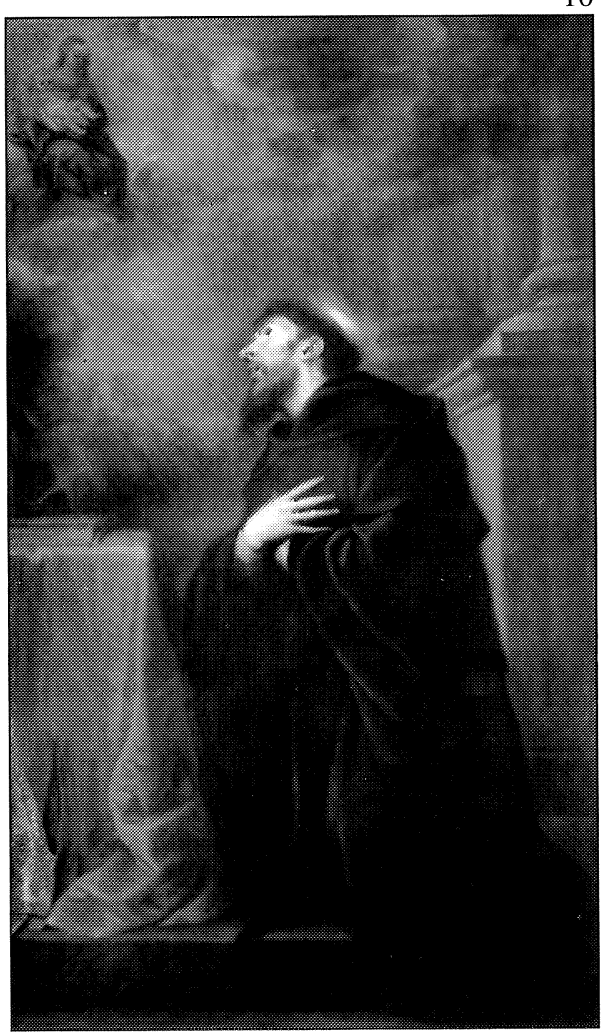

Fig. 7. Cerezo: Cabeza femenina. Biblioteca Nacional. Madrid.

Fig. 8. Cerezo: Estigmatización de San Francisco. Museo del Prado.

Fig. 9. Cerezo: Cabeza varonil. Museo del Prado.

Fig. 10. Cerezo: San Agustín. Museo del Prado. 
(Fig. 26). Aunque los estados anímicos de ambos Santos parecen diferentes y la técnica, a base de esfuminados muy finos, es la característica de Carreño, conviene reseñarle como una prueba más de esa similitud estilística entre maestro y discípulo.

Otra cabeza que se puede atribuir a Cerezo es una hermosa Cabeza varonil (Fig. 9) ${ }^{30}$ conservada en el Museo del Prado como anónima. Está concebida en un inteligente perfil que hace una visión de sotto in su, y su rostro característico de sus modelos masculinos, reproduce con bastante afinidad el de su San Agustín al óleo de dicho museo (Fig. 10) ${ }^{31}$. Es similar particularmente la inclinación de la cabeza (inversa en el dibujo), la punta y el puente de la nariz (idénticos en ambos casos), los carnosos pero ascéticos labios semientreabiertos (tan caros al pintor) y el hermoso y compacto cuello prolongado en el dibujo sin interrupción desde el mentón al haberse recortado la profusa barba del santo agustino.

El parecido con otros rostros de sus lienzos, especialmente con los de sus «San Franciscos» (Wisconsin, Catedral de Valencia, etc.), permiten considerar al dibujo como un nuevo «patrón» también con recuerdos canescos (a pesar de lo habitual del escorzo) que Cerezo reaprovechó frecuentemente en los cuerpos de sus santos protagonistas. En lo técnico la cabeza muestra claramente el estilo gráfico de Cerezo. Combina con gran perfección el lápiz negro graso y la sanguina, y su modelado se hace a base de rayitas paralelas destacándose por su enorme valor plástico los trazos cortos y aislados del mentón.

La fecha de realización de este magnífico dibujo podría corresponder a la del mismo cuadro de «San Agustín» firmado en 1663.

La siguiente cabeza atribuible a Cerezo, si bien con más dudas que las anteriores al no conocerse ningún ejemplo parangonable en su producción, es la de un bello Muchacho que se conserva igualmente como anónima en el Museo del Prado (Fig. 11) ${ }^{32}$.

$\mathrm{Su}$ rostro recuerda lejanamente al de un personaje que aparece en algunos lienzos del joven Velázquez (El Aguador, Vieja friendo huevos, etc.), identificado con un aldeanillo que tenía como modelo, lo que de ser así quizá le emparente con el dibujo de la Muchacha de la Biblioteca Nacional, también con ligeros recuerdos velazqueños según apreciamos anteriormente.

La técnica a base de sanguina es desde luego la habitual del artista burgalés. Obsérvese el trazo fino del perfil de la cara similar al de un torso masculino que analizaremos a continuación (Fig. 13) y el modo de hacer las pestañas, a base de manchas corridas acabadas en punta, como en la Muchacha de la Biblioteca Nacional. Por otro lado, la forma de hacer la mandíbula casi plana por medio de una línea horizontal que demarca el plano del cuello, muestra claramente el «automatismo» del artista en este tipo de soluciones técnicas, pues se resuelve de la misma manera que su Cabeza juvenil del Prado.

En el dorso lleva un apunte muy mediocre de unas piernas desnudas, acaso de mujer, difícilmente clasificables en el estilo del pintor.

Cabe todavía adscribir en este interesante grupo de cabezas dos de niños conservados en el mismo Museo que las anteriores con la atribución a Francisco Ignacio Ruiz de la Iglesia.

La primera (Fig. 12) ${ }^{33}$, con una visión de arriba abajo y girada levemente hacia la izquierda, forma parte de un grupo de cuatro cabezas infantiles en soportes diferentes, reunidas facticiamente en una misma hoja. Está realizada a lápiz negro y clarión, y su técnica difiere notablemente de las tres restantes en los perfiles muy finos repasados con lápices duros, y en el volumen denso con gran sentido escultórico: fórmulas básicas en los dibujos más «acabados» de Cerezo.

\footnotetext{
${ }^{30}$ Id., p. 171 , F.A. $730.206 \times 150 \mathrm{~mm}$

31 Buendía y Gutiérrez, lám. p. 47 , cat. 42 , p. 141.

32 F.A. $908.90 \times 80$ mm. Pérez Sánchez, Ob. cit. Museo del Prado, 1972, p. 171.

33 Id., F.D. $1298,147 \times 122$ mm., p. 127 .
} 

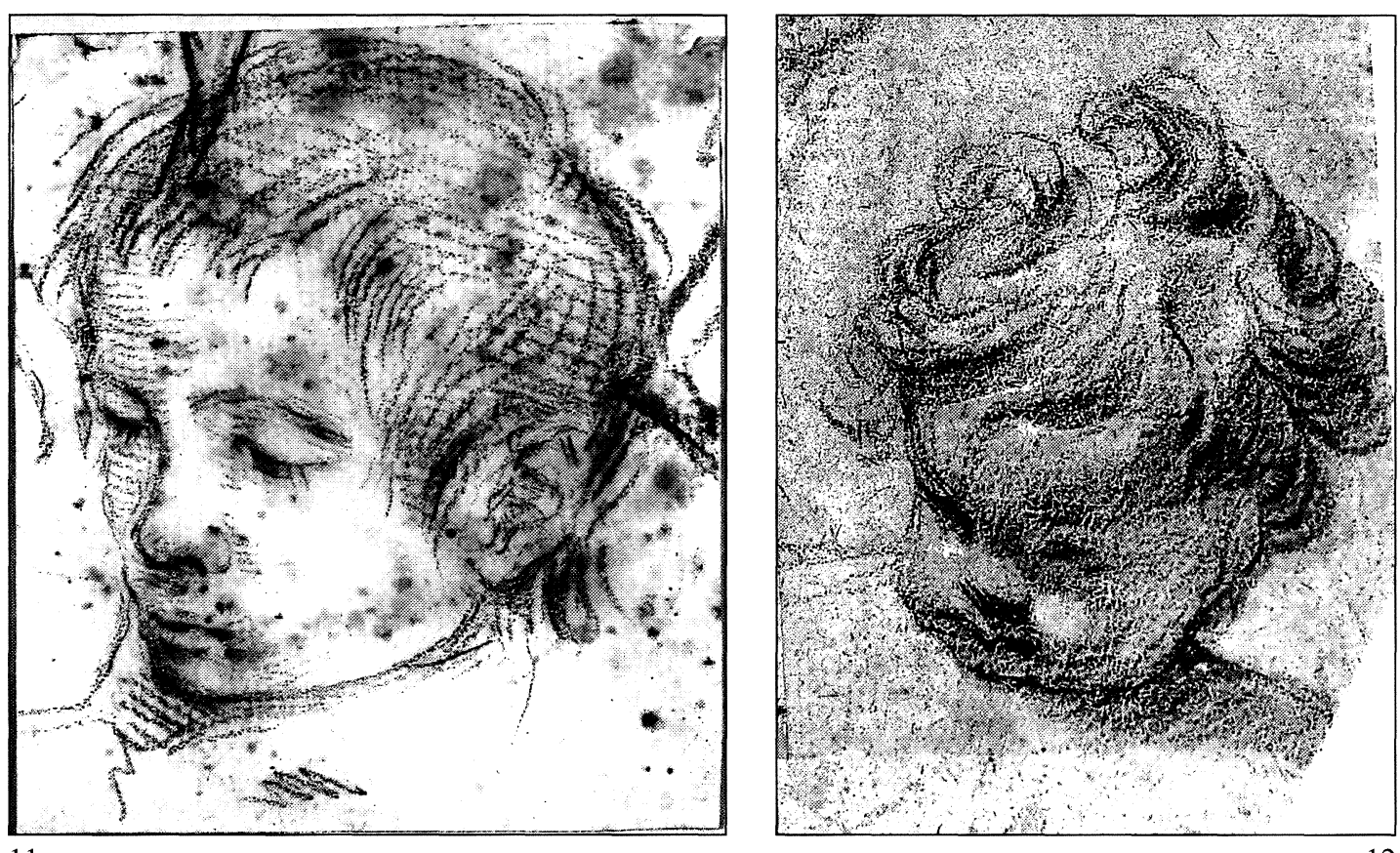

11

13
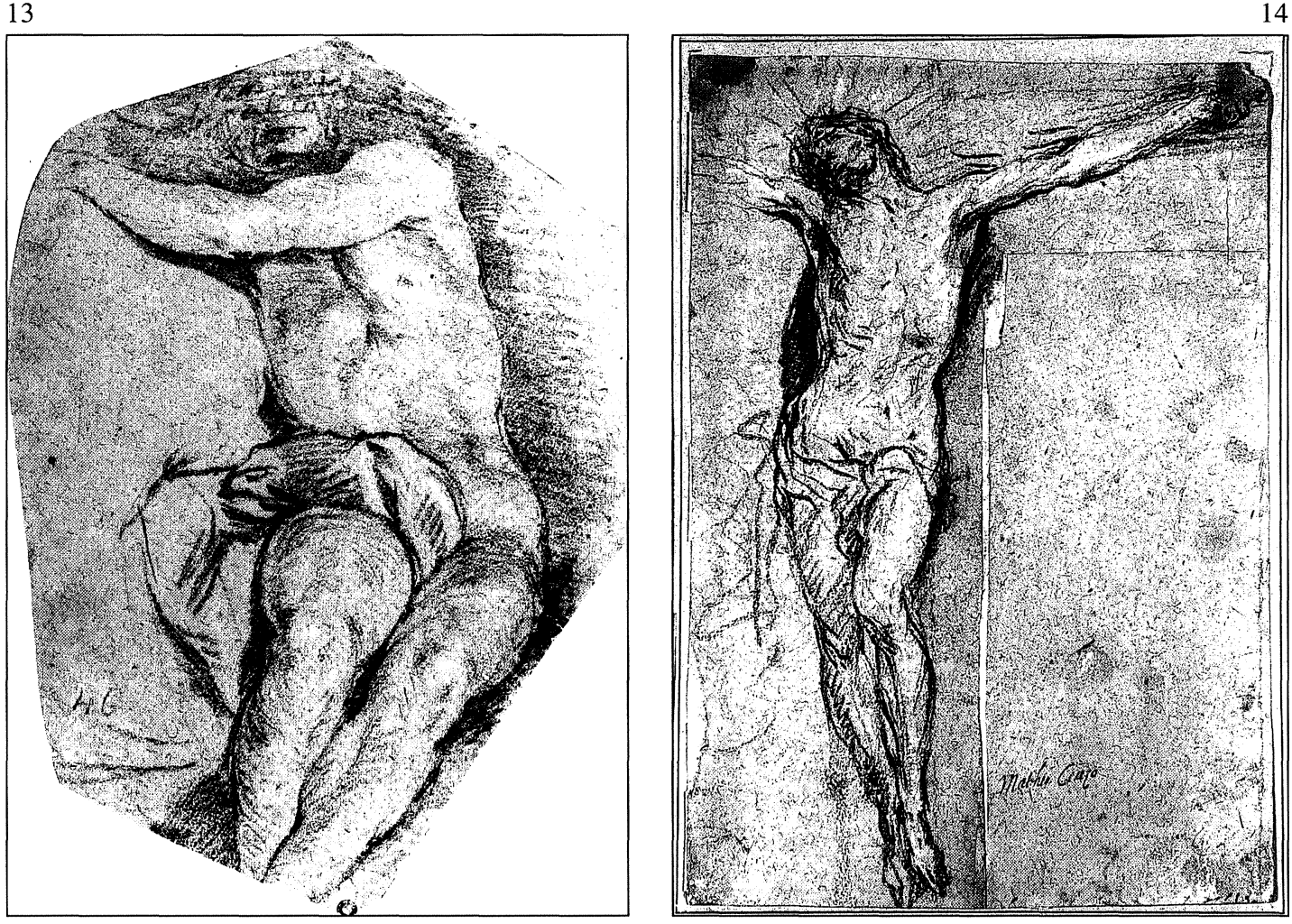

Fig. 11. Cerezo: Cabeza de muchacho. Museo del Prado.

Fig. 12. Cerezo: Cabeza infantil. Museo del Prado.

Fig. 13. Cerezo: Desnudo masculino. Casa de la Moneda. Madrid.

Fig. 14. Cerezo: Cristo crucificado. Museo del Prado. 
El tipo infantil por otro lado es similar a algunos de los modelos más logrados del pintor. Obsérvese su semejanza con el Niño Jesús de la Aparición de la Virgen a San Francisco de la colección Martorell, casi idéntico, o con el del angelito que aparece sujetando varios ramos de rosas y azucenas en la Inmaculada de la colección Benavites (Fig. 22).

En el dorso lleva también un apunte de una mano abierta, con dedos largos y estilizados, que recuerda a algunas de su muestrario más habitual.

La otra cabeza de niño ${ }^{34}$, atribuida igualmente a Ruiz de la Iglesia, presenta las mismas características técnicas que la anterior, si bien su posición es más frontal.

En cuanto a los dibujos de cuerpos, figuras enteras y medias figuras que se pueden atribuir a Cerezo, conviene subrayar como nota dominante su típica funcionalidad práctica transferible siempre a lienzo. Esta funcionalidad le aparta un tanto de la concepción del dibujo como obra de arte en sí mismo.

El primero en este orden podría ser un excelente estudio de un Desnudo masculino, tal vez una figura para un «Cristo en su flagelación», que guarda el Museo de la Casa de la Moneda (Fig. 13) ${ }^{35}$.

Está realizado a lápiz negro y sanguina en su fórmula más habitual y muestra el torso bien resuelto de un hombre semidesnudo en una compleja posición que le mantiene sentado con los brazos en alto desviados hacia un lado. El dibujo presente el mismo perfil vacilante del «Cristo crucificado» del Prado (Fig. 14), repasado con lápiz graso y las mismas sombras oscuras pegadas junto al cuerpo para realzar el objeto y crear profundidad. Obsérvese por ejemplo la zona de la axila similar a la del Cristo del Prado (ésta más pequeña) o la de la cadera, también elaborada a manchones.

Asimismo es característico la indefinición de la cabeza al modo de su «San Juan Bautista» florentino, y el modelado plástico de la materia a base de rayitas paralelas muy pequeñas apreciables aquí en la tela que cruza la pierna.

No deja de ser interesante destacar el enorme parecido que presenta este cuerpo con el Cristo y el alma cristiana de Velázquez (que, como vamos viendo, parece inspirarle lejanamente en algunos de sus dibujos), a pesar de que su postura sea en realidad la clásica en los grabados y en los «modelos» de academia.

A este respecto vale la pena recordar las palabras de Palomino que hacen a Cerezo «frecuentando las academias, y pinta(ndo) por el natural... sólo por estudio, y copiando diferentes originales de Palacio» ${ }^{36}$.

Mayor finalidad parecen tener algunos estudios o patrones de figuras completas atribuibles a su mano. Es el caso de dos dibujos, uno con una Figura suplicante que guarda el Museo de los Uffizi, y otro con un San Isidro Labrador de la madrileña Casa de la Moneda.

La Figura suplicante (Fig. 15) ${ }^{37}$, «rasguño» o primera idea para una composición, lleva una firma apócrifa con el nombre de Alonso Cano puesta ya en entredicho por Pérez Sánchez quien consideró el dibujo cercano al círculo de Carreño, concretamente de Mateo Cerezo.

Analizados sus caracteres gráficos se comprueba en efecto que sus trazos quebrados, yuxtapuestos en ángulos y tendentes a dar un ligero aspecto leñoso a la composición son similares a los de su «San Juan Bautista» de la misma colección.

Presenta un carácter de ensayo con rectificaciones y tanteos en la posición de la cabeza y las piernas, por lo que se le podría considerar un «esqueleto» de una presumible «Asunción»

\footnotetext{
34 Id., F.D. $1999,71 \times 66$ mm., p. 127.

$35270 \times 190 \mathrm{~mm}$. Durán González-Meneses, Catálogo de los dibujos de los siglos xvi y xvII de la Colección del Museo de la Casa de la Moneda, Madrid, 1980, pp. 51-52, lám. 118, p. 82. Como desnudo femenino.

36 Palomino y Velasco, vol. 3, p. 332.

37 Núm. cat. 10266 S. $272 \times 180$ mm. Pérez Sánchez, Ob. cit. Mostra de disegni..., p. 114, núm. 129, lám. 102.
} 

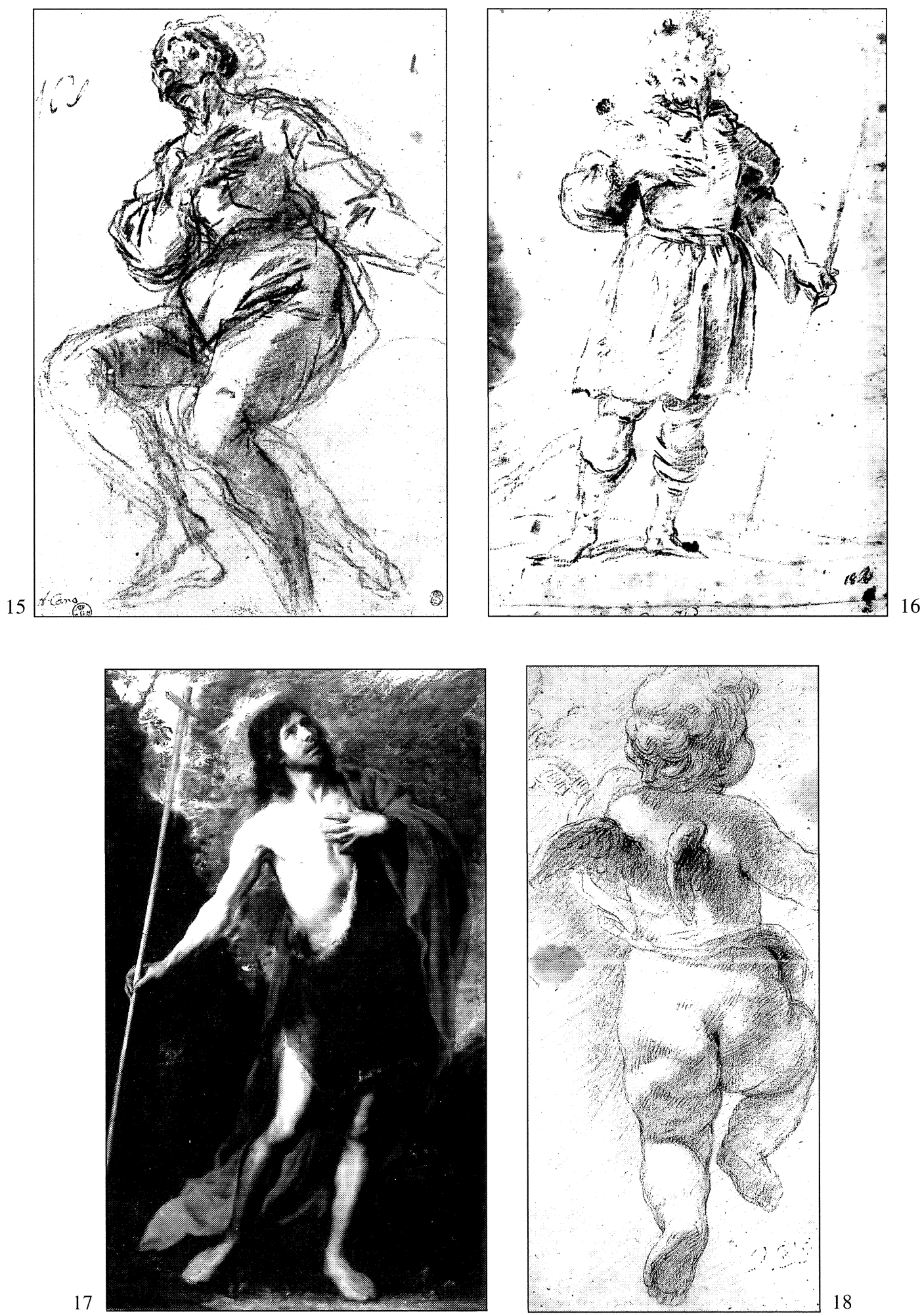

16

Fig. 15. Cerezo: Figura suplicante. Museo de los Uffizi. Florencia. Fig. 16. Cerezo: San Isidro Labrador: Casa de la Moneda. Madrid.

Fig. 17. Cerezo: San Juan Bautista. Staatliche Kuntsammlunge. Kassel. Fig. 18. Cerezo: Ángel niño. Museo del Prado. 
de la Virgen que tiene en Cerezo su paralelo más próximo en la del convento vallisoletano de Jesús y María.

Su composición recuerda de nuevo las fórmulas empleadas por Carreño —ahora derivadas de Rubens-en temas similares.

Técnicamente representa uno de sus exponentes gráficos más característicos de formas abiertas, estando realizado a lápiz negro y sanguina en su modo más habitual.

Como rasguño se puede decir que es algo inferior al de su «Cristo crucificado», si bien expresa la misma fuerza gráfica.

El San Isidro Labrador (Fig. 16) ${ }^{38}$, dibujo algo más elaborado que el anterior pero con la misma frescura del «non finito» acaso porque copia algún modelo predeterminado o corregido, o simplemente por su habilidad en la composición que le hace no tener tanteos, fue insinuado ya por Reyes Durán como de Cerezo entre Carreño, Escalante y Moreno.

Está realizado con las mismas soluciones técnicas que los anteriores, es decir, dejando indeterminada la cabeza para poder ser combinada con otros patrones, y haciendo un perfilado intermitente con el lápiz negro graso al estilo de su «San Juan Bautista» que da a la imagen una gran sensación vacilante.

Lo destacado de la figura como un objeto aislado podría hacer pensar en un nuevo «patrón» para una composición hoy sin localizar, pero cuyo valor funcional le sirvió también al artista para hacer otras estructuras, como la de su San Juan Bautista del Staatliche Kunstsammlunge de Kassel (h. 1665) (Fig. 17) ${ }^{39}$ realizada a la inversa.

Otro dibujo igualmente atribuible a su mano y que se puede considerar un interesantísimo ejemplo gráfico de «modelo» definitivo, es el de un Ángel niño conservado en el Museo del Prado con la atribución a Carreño (Fig. 18) ${ }^{40}$.

Aunque la precisión de su estilo le emparenta con algunos diseños del pintor asturiano, como el retrato de «Carlos II» del Prado, en éste Carreño ha hecho un sutilísimo difuminado de perfiles casi imperceptibles que en el «Ángel» no existe, estando sus contornos claramente especificados a lápiz fino, lo que proporciona a la figura un fuerte sentido escultórico típico de Cerezo.

Su modelado a base de lápiz negro, sanguina y clarión, es el mismo que se oberva en su «Cabeza juvenil», siendo muy similar el modo de resolver los perfiles (repasados a sanguina y lápiz negro) y el tratamiento del cabello con tendencia a arremolinarse.

A juzgar por el esmero con que el artista ha aplicado las sombras distribuyendo las luces a base de clarión e intentando establecer las calidades no sólo de la piel tersa del niño sino también del cendal vaporoso que cubre su cintura, o del plumón de las alas, cabe pensar en un modelo predilecto de ángel niño que en Carreño apenas tiene correspondencia (lo más próximo es un angelito que aparece en la peana de la Inmaculada de Vitoria -1666-) y que en Cerezo tiene vivos ejemplos en las bases angélicas de sus más bellas Inmaculadas, como las de la col. Benavites (h. 1664-1665) (Fig. 22), col. particular sevillana (h. 1663-1664), y Ayuntamiento de San Sebastián (h. 1665-1666). En todas Cerezo resume el mismo tipo de angelito, es decir, vuelto de espaldas, con la pierna derecha flexionada y con el cendal enroscado a la cintura pasando por debajo del ala para posarse airosamente sobre el hombro izquierdo. Este modelo de ángel hizo sugerir a Buendía y Gutiérrez que se trataba de «una de las más afortunadas figuras de este tipo en la pintura de Cerezo» ${ }^{41}$.

Como ocurre con otros estudios del artista el modelo es un patrón que no se corresponde

\footnotetext{
$38250 \times 139$ mm. Durán González-Meneses, p. 78, núm. cat. 103, lám. p. 187.

39 Buendía y Gutiérrez, lám. p. 93, cat. 65, pp. 156-157.

40 F.D. 29. $270 \times 125$ mm. Pérez Sánchez, Ob. cit. Museo del Prado, 1972, p. 73.

41 Buendía y Gutiérrez, p. 68.
} 
19
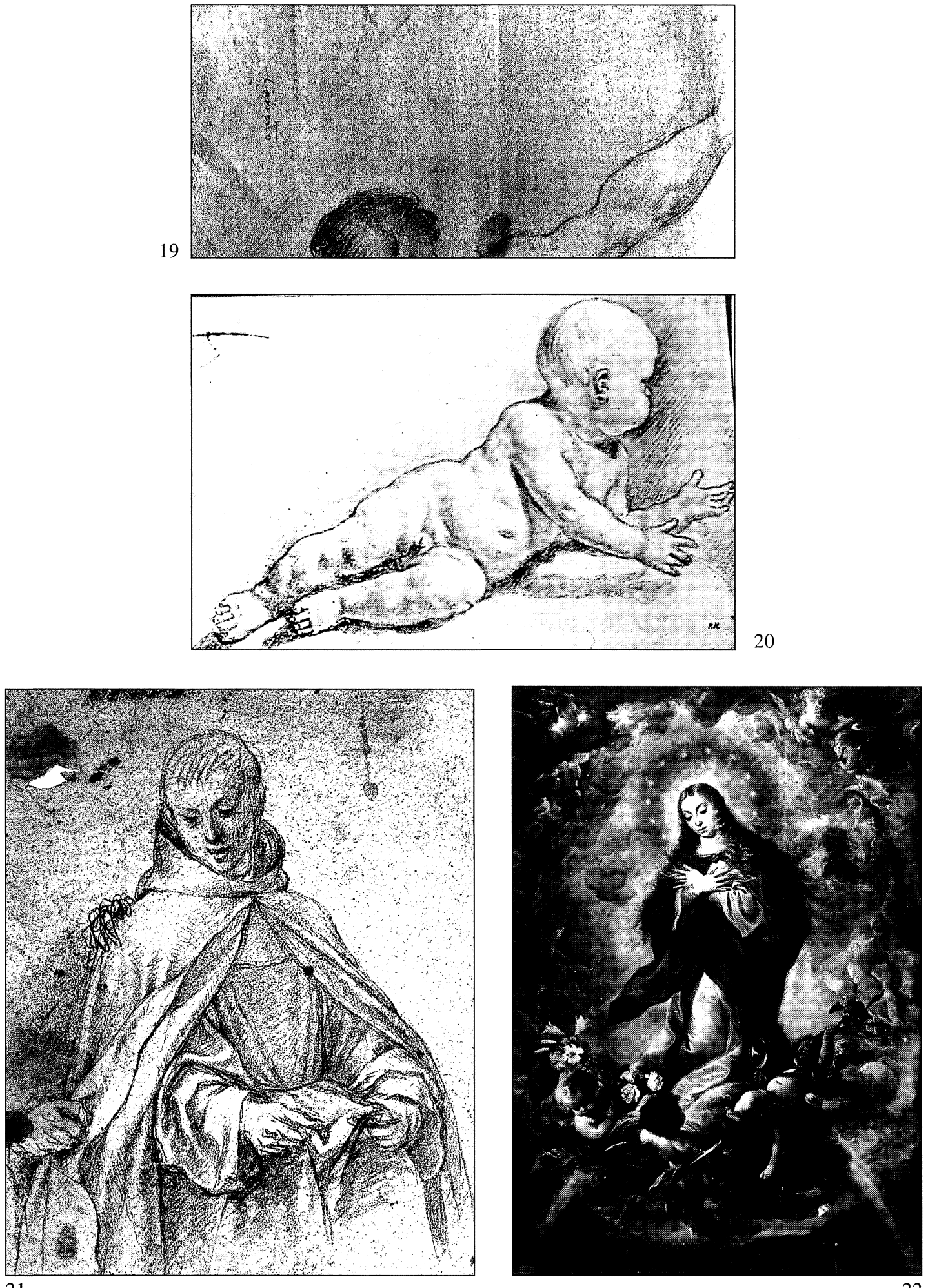

Fig. 19. Cerezo: Fragmento de Academia. (Reverso del dibujo Ángel niño). Museo del Prado.

Fig. 20. Cerezo: Estudio de niño. Comercio. Nueva York.

Fig. 21. Cerezo: San Diego de Alcalá. Biblioteca Nacional. Madrid.

Fig. 22. Cerezo: Inmaculada Concepción. Col. Benavites. Madrid. 
exactamente con los tipos más dinámicos transferidos en sus lienzos, siendo el de la col. Benavites el que traduce más fielmente su perfil — tal vez una de las mejores cualidades del estudio- y los de Sevilla y San Sebastián su verticalidad.

El dibujo lleva también en su reverso un «apunte fragmentado de cabeza y brazo derecho» que recuerda bastante al de la «Academia» del Museo del Prado (Fig. 19).

Similar a este modelo de «Ángel niño» es otro de un Niño recientemente aparecido en el mercado neoyorquino con la atribución a Cerezo (Fig. 20) ${ }^{42}$. Procede al parecer de la colección P. Huart (?), según indican unas iniciales «P. H.» en el extremo inferior derecho, y muestra a un niño semitumbado mirando hacia atrás en un dificilísimo escorzo que ensalza notablemente su perfil.

Sin poder confirmar la autenticidad del dibujo al no tener más referencias que una fotografía, su ejecución parece desde luego similar a la que presentan otros diseños del artista. La forma de precisar los perfiles tendentes a las formas cerradas, el subrayado típico de fondo con líneas paralelas, y la combinación del lápiz negro con la sanguina, son las características de Cerezo, por lo que autorizan a considerar a este dibujo como una obra suya. Por otra parte, el perfil del niño es muy similar al del «Ángel» del Prado — compárense esos hermosísimos mofletes de la cara - y la tipología infantil, si bien es diferente a la de otros de sus estudios, es también la típica de su muestrario según puede observarse en el «Niño Jesús» de los lienzos vallisoletanos del convento de Jesús y María.

En cualquier caso, la atribución a Cerezo no deja de ser significativa al no ser frecuente ésta en los dibujos conocidos del artista.

Un diseño que se puede también relacionar con el estilo gráfico de Cerezo es un interesante San Diego de Alcalá de medio cuerpo conservado como anónimo en la Biblioteca Nacional de Madrid (Fig. 21) ${ }^{43}$.

El dibujo presenta un modelo definitivo de Santo para una composición con más personajes (según indican sendas manos que agarran la capa) que no se llegaron a realizar seguramente por su mismo valor de «figura» como modelo único.

Está realizado a sanguina con ligerísimos toques de clarión en la manga izquierda, manos y nariz, y su técnica es la habitual de Cerezo. Establece perfiles muy marcados, con un gran sentido escultórico, y sus sombras se elaboran con un sutil rayado que recuerda al de sus cabezas infantiles del Museo del Prado.

El tipo humano presenta analogías muy concretas con el de sus «Inmaculadas» Benavites (Fig. 22) y San Sebastián, especialmente en el óvalo de la cara, ojos, cejas y narices. Su disposición también está en consonancia con el lienzo de Santo Tomás de Villanueva del Museo del Louvre.

Como en otras ocasiones, Cerezo parece haberse inspirado en modelos escultóricos de Alonso Cano. Su rostro recuerda al de una talla de «San Diego de Alcalá» conservada en el Museo granadino del Palacio de Carlos $\mathrm{V}^{44}$. Compárese por ejemplo la similitud de los ojos y las cejas muy oblicuos, y la forma de tratar el cabello a base de trazos rectos. Por otro lado, el tratamiento de los paños es muy semejante a los del ya mencionado «San Antonio de Padua» murciano.

El diseño se podría fechar en torno a los últimos años de su producción si consideramos su maestría técnica y su semejanza estilística con los cuadros de cronología más tardía.

Para terminar, se pueden atribuir al pintor una serie de dibujos con composiciones «prede-

\footnotetext{
$42165 \times 239$ mm. Catálogo de ventas Sotheby's, Old Master Drawings, Enero 1987, p. 21, núm. 70 .

$43197 \times 248 \mathrm{~mm}$. Barcia, pp. 121-122, núm. 588 .

${ }^{44}$ Wethey, 1983, láms. 141 ó 143.
} 

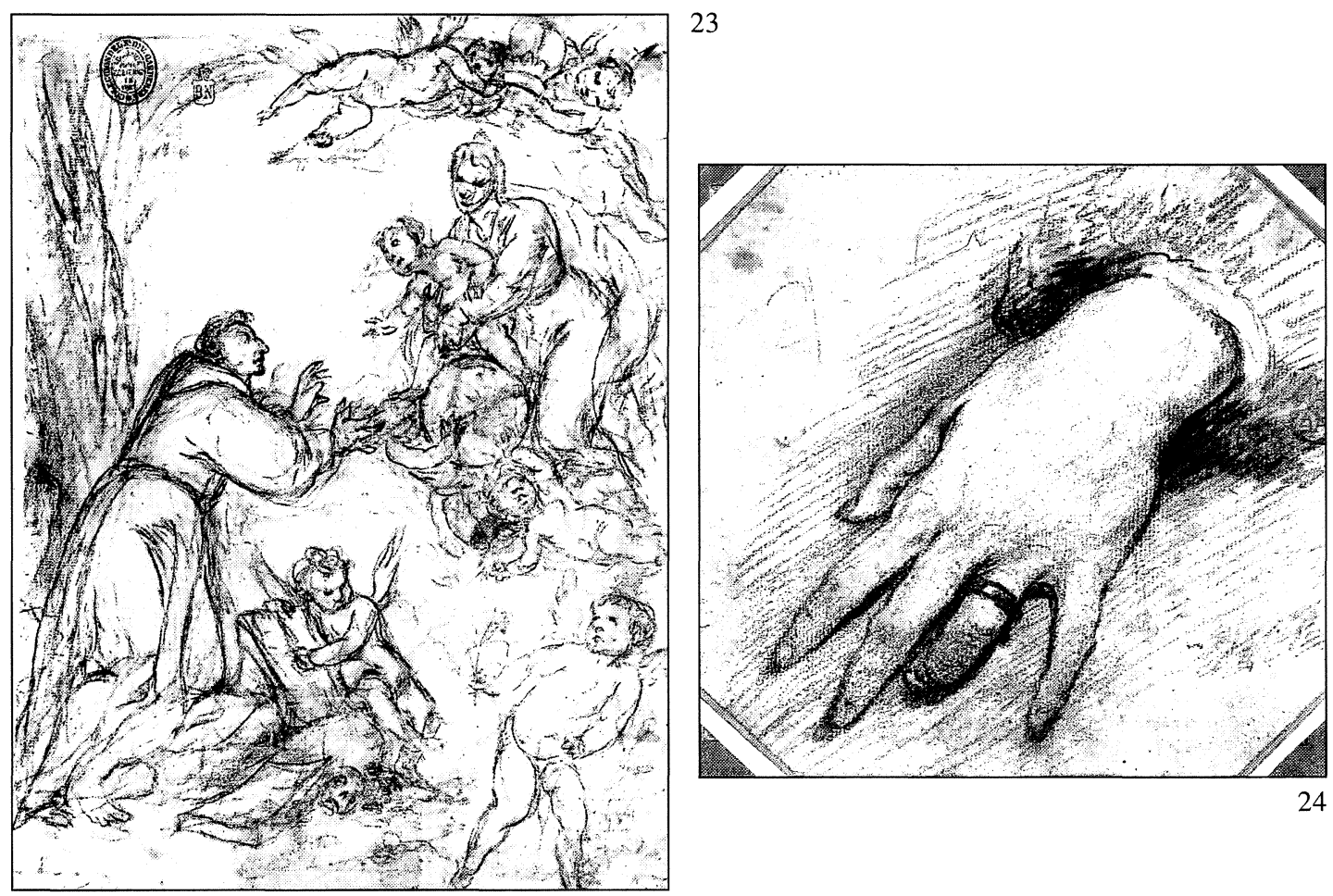

25
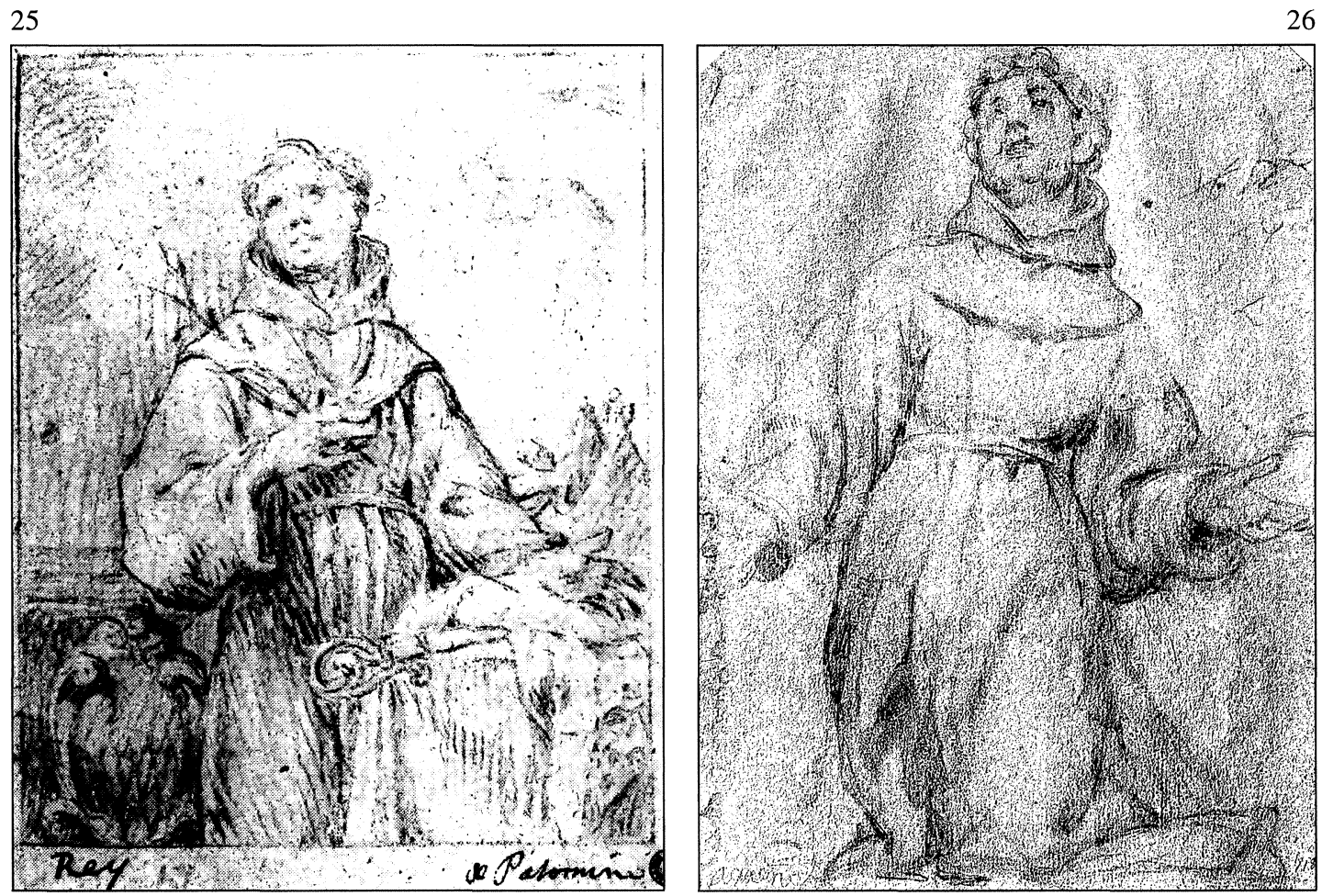

Fig. 23. Cerezo: Aparición de la Virgen a Félix de Cantalicio (?). Biblioteca Nacional. Madrid.

Fig. 24. ¿Cerezo? Estudio de mano femenina. Real Academia de Bellas Artes de San Fernando. Madrid.

Fig. 25. Círculo Cerezo: Fraile. Casa de la Moneda. Madrid.

Fig. 26. ¿Carreño?: San Francisco arrodillado. Museo del Prado. 
terminadas», que revelan la manera de enfrentarse Cerezo a un tema impuesto con rectificaciones y tanteos en los encuadres de las figuras.

Uno de ellos es una Aparición de la Virgen a San Félix de Cantalicio (?) de la Biblioteca Nacional de Madrid (Fig. 23).

Atribuido por Barcia a Francisco Rizi ${ }^{45}$, su estilo en realidad tiene poco que ver con los habituales trazos sinuosos del pintor mádrileño. El diseño presenta un aspecto enmarañado similar al de La Virgen y el Niño adorados por Santos de la Academia de San Fernando, también de composición predeterminada. Posee, además, una serie de tecnicismos habituales en el «automatismo» artístico del pintor, como por ejemplo el tipo de modelo infantil. Nos referimos en efecto al niño que sujeta un enorme infolio, similar en su barriga flácida al que porta un ramo de lirios en la Aparición de la Virgen a San Francisco del Museo Lázaro Galdiano (h. 1665); al que lleva una corona con la cabeza semioculta por la posición del brazo, muy próximo al que transporta una rosa en la Inmaculada del Ayuntamiento de San Sebastián; o al que permanece de pie en la parte derecha de la composición con la misma estructura de muslos y piernas que el que figura en idéntico «contraposto» en el cuadro anteriormente citado de San Sebastián. No deja de ser indicativo por otro lado que la composición, muy similar a la de sus «Apariciones de la Virgen a San Francisco de Asís» (Museo Lázaro Galdiano y Col. Martorell), se resuelva también en un exterior con alusiones a la naturaleza poco frecuentes en este tipo de escenas.

Desde el punto de vista técnico el dibujo presenta un estilo gráfico muy diverso del de sus formas abiertas o cerradas. Hace correcciones y tanteos como en la «Figura suplicante» - obsérvense las piernas del santo o las de los niños que portan la corona- a la vez que cuida con mayor naturalismo el acabado de las formas.

Está realizado a lápiz negro repasado con toques de carboncillo en los perfiles de las figuras y se puede considerar un «rasguño» o primer apunte para una composición muy cercana a su encargo vallisoletano del convento de San Francisco (h. 1664).

Aún se puede relacionar con el arte de Cerezo otro dibujo de una bonita Mano femenina conservado en la Academia de Bellas Artes de San Fernando ${ }^{46}$ (Fig. 24).

Atribuida a Carreño por Menéndez Pidal en la catalogación que hizo de la colección, el estudio se puso ya en duda por Velasco, quien le señaló con una interrogación sin precisar su autor.

Se trata de un pormenor bastante notable - véase el escorzo del dedo anular-, pero muy poco significativo a la hora de poderse atribuir a un artista concreto dada su visión pormenorizada. No obstante, el dibujo presenta algunos caracteres básicos en el estilo de Cerezo, como el perfilado intenso de la mano - algo más grueso que el habitual-, y el subrayado denso junto a las yemas de los dedos formando manchas oscuras que recuerdan inmediatamente a las sombras pegadas que hizo el pintor burgalés en la espalda del «Cristo crucificado», o a las del «torso masculino» de la casa de la Moneda.

El tipo de mano, no obstante, se podría relacionar con el estilo de Antolínez, según comunicación oral del profesor Pérez Sánchez.

En cualquier caso, esta mano - finísima-, si fuese obra de Cerezo podría considerarse un apunte para un retrato; faceta de la que actualmente no se conoce nada seguro, salvo las palabras de Palomino, que le hace «retratando a algunos sólo por estudio» ${ }^{47}$.

$45207 \times 275$ mm. Barcia, p. 97, núm. 464.

${ }^{46} 147 \times 150$ mm. Velasco, M., Catálogo de la Sala de dibujos de la Real Academia de San Fernando, Madrid, 1941, p. 34, núm. 74; Ciruelos Gonzalo, A. y García Sepúlveda, M.P., «Inventario de dibujos de la Real Academia de Bellas Artes de San Fernando (IV)», Boletín de la Real Academia de Bellas Artes de San Fernando, 1989, n. 69, p. 289, núm. inv. 2146.

47 Véase nota 36. 
Finalmente, un dibujo anónimo que se puede poner también en relación con el estilo de Mateo Cerezo es un Fraile, acaso «San Antonio», del Museo de la Casa de la Moneda ${ }^{48}$ (Fig. 25).

La obra, de cronología seguramente posterior, presenta afinidades técnicas muy concretas con su modo gráfico, por lo que conviene considerarla al menos de su círculo artístico. La forma inconstante de repasar los perfiles, la manera de modelar la materia a base de rayitas muy pequeñas, o la ayuda del clarión para conseguir un mayor efecto pictórico, son las propias de Cerezo. Pero sobre todo, lo que más le relaciona es el tratamiento del rostro, similar al de su «San Francisco estigmatizado» del Prado, y la forma de abultar el hábito por debajo del cordón, a modo de una enorme panza, apreciable sólo en algunos de sus «San Franciscos», como el del Elvehjem Museum of Art de Wisconsin.

El dibujo, por tanto, se podría considerar de algún artista madrileño de finales del siglo XVII, seguidor (y conocedor) de la técnica del gran dibujante burgalés.

$48146 \times 115 \mathrm{~mm}$. Lleva una inscripción con letra del siglo Xvil que dice «de Palomino» (indicando quizás más posesión que ejecución). Durán González-Meneses, pp. 51-52, lám. 58, p. 146. 